V.2, N.1, 2018

DOI: $10.33947 / 2595-6264-v 2 n 1-3617$

\title{
APLICATIVO ANDROID PARA AVALIAR A QUALIDADE DA PULVERIZAÇÃO EM CONDIÇÕES DE CAMPO
}

\section{EVALUATION OF SPRAY QUALITY UNDER FIELD CONDITIONS BY ANDROID APP}

\author{
Bruno Alberto Soares Oliveira ${ }^{1}$, Servilio Assis², Robson Shigueaki Sasaki ${ }^{3}$
}

RESUMO: Um dos métodos utilizados para avaliar a qualidade da pulverização em campo, é por meio de etiquetas hidrossensíveis, que após as pulverizações é digitalizada e analisada por meio de programas computacionais. Este método requer um mínimo de conhecimento e a necessidade de um computador. Para facilitar as análises de etiquetas hidrossensíveis em campo, objetivou-se desenvolver um aplicativo em plataforma Android. Utilizou-se a linguagem de programação Java para Android e a biblioteca de Visão Computacional OpenCV, onde foram implementadas no ambiente de desenvolvimento Eclipse Kepler. As imagens capturadas foram convertidas para o tipo Mat e na segmentação fez-se o uso de técnicas de processamento digital de imagens. Todas as funcionalidades utilizadas foram da biblioteca OpenCV. O sistema foi desenvolvido para determinar principalmente a densidade de gotas por unidade de área e o diâmetro mediano volumétrico (DMV). Com o aplicativo desenvolvido, realizou-se a validação do sistema proposto. Para isso, obteve-se cinco etiquetas hidrossensíveis e submeteu-se a análise em quatro diferentes aparelhos móveis. Ao final, observou-se que o aplicativo desenvolvido realizou de maneira satisfatória as análises das etiquetas. Para a densidade de gotas, entre um aparelho e outro, apresentaram coeficiente de variação (CV) de no máximo 11,15\%. Para o DMV, o CV máximo foi de 3,53\%.

PALAVRAS-CHAVES: Etiqueta hidrossensível. Aplicativo Android. Monitoramento da pulverização.

ABSTRACT: Evaluation of spray quality under field conditions may be done by water sensitive papers that are scanned and analyzed by computer softwares after spraying. This method requires a minimum of knowledge and the need of a computer. To facilitate the analysis of water sensitive papers in the field, it is aimed to develop an Android app. It was used the Java programming language for Android and the OpenCV Computer Vision Library that were implemented in Eclipse Kepler. The captured images were converted to Mat type and in the segmentation it was used the digital image processing techniques. All the implemented features were from the OpenCV library. The system was mainly developed to determine the droplets density per unit area and the volume median diameter (VMD). Done the development of the application, the validation of the proposed system was carried out. To do so, five water sensitive papers were subjected to analysis in four different smartphones. In the end, it was observed that the developed application performed satisfactorily the analyzes of the water sensitive papers. Droplets density presented coefficient of variation (CV) of maximum $11.15 \%$ between the smartphones. For the VMD, the maximum CV was $3.53 \%$.

KEYWORDS: Water sensitive papers. Android app. Spray monitoring.

\footnotetext{
Mestrando em Engenharia Elétrica na Universidade Federal de Minas Gerais (UFMG) na linha de pesquisa Inteligência Computacional.

Programa de Pós-Graduação em Engenharia Elétrica - Universidade Federal de Minas Gerais - Av. Antônio Carlos 6627, 31270-901, Belo Horizonte, MG, Brasil

3 Doutorado em Engenharia Agrícola pela Universidade Federal de Viçosa, Brasil (2014). Professor do Ensino Básico, Téc. e Tecnólogo do Instituto Federal Minas Gerais, Brasil
} 
APLICATIVO ANDROID PARA AVALIAR A QUALIDADE DA PULVERIZAÇÃO EM CONDIÇÕES DE CAMPO Bruno Alberto Soares Oliveira, Servilio Assis, Robson Shigueaki Sasaki

\section{V.2, N.1, 2018}

\section{INTRODUÇÃO}

O monitoramento da qualidade de uma aplicação é de grande importância para verificar se de fato está ocorrendo a deposição de gotas sob o alvo, penetração de gotas no dossel, bem como verificar as perdas de agrotóxicos para o meio ambiente. Além da deposição de gotas sob o alvo é importante também, monitorar o tamanho das gotas durante a pulverização, pois a eficiência e a qualidade da aplicação estão intimamente relacionadas ao espectro de gotas. Gotas muito finas podem favorecer a deriva (RODRIGUES et al., 2015) e gotas grossas favorecem o escorrimento (SILVA et al., 2014).

Todas as máquinas empregadas em campo devem ser utilizadas de maneira eficiente, destacando-se os equipamentos que realizam a aplicação de agrotóxicos. O uso de agrotóxicos, sem o emprego adequado da tecnologia de aplicação, pode causar a contaminação do meio ambiente, deixar resíduos nos alimentos, e aumentar o risco de intoxicação por parte dos trabalhadores rurais. Há relatos de pulverizações ineficientes com excesso ou déficit de ingrediente ativo no alvo, e em alguns casos, mais de $50 \%$ dos agrotóxicos utilizados são desperdiçados porque não atingem os alvos desejados. Chaim et al. (1999) na cultura do tomate e feijão presenciaram perdas entre 59 e $76 \%$ dependendo do porte das plantas. Em videiras, Chaim et al. (2004) observaram perdas de até $39 \%$.

Em uma aplicação de agrotóxicos, parâmetros como a correta identificação do problema, seleção dos produtos e equipamentos, regulagem e calibração do pulverizador, espectro e população de gotas, as condições meteorológicas, e a avaliação da qualidade da pulverização são primordiais e, determinam a qualidade de uma aplicação.

A avaliação da qualidade de uma aplicação de agrotóxicos é de grande importância para verificar se de fato está ocorrendo a deposição de gotas sob o alvo, bem como verificar as perdas de agrotóxicos para o meio ambiente. As avaliações em campo, geralmente são realizadas com etiquetas hidrossensíveis (BAESSO et al., 2014). Essas etiquetas são de papel recobertas por uma camada de azul de bromofenol, que em contato com a água, torna-se azul diante a mudança do pH (TURNER; HUNTINGTON, 1970).

Vitória e Campanharo (2016) relatam que a utilização de etiquetas de papel hidrossensível em experimentos ligados à tecnologia de aplicação vem sendo bastante utilizados entre os pesquisadores, produtores e extensionistas de áreas relacionadas ao controle químico, oferecendo importantes informações a respeito dos fatores interligados ao controle de plantas daninhas, pragas e doenças.

Estas avaliações quando realizadas visualmente pode acarretar erros, e por meio de softwares o trabaIho em campo é oneroso visto que deve-se digitalizar as etiquetas para posterior análise, empregando-se um computador e software específico para tal finalidade.

Por sua vez as etiquetas são analisadas visualmente por meio de um gabarito e lupa ou então com o auxílio de softwares para análises de imagens (GARCIA et al., 2004). Estas análises quando realizadas visualmente além de elevado tempo nas análises é um processo desgastante, pois necessita avaliar um número elevado de gotículas (PESSOA e CHAIM, 1999), e ainda é altamente susceptível a erros. Por meio de softwares o trabalho em campo é oneroso visto que se devem digitalizar as etiquetas para posterior processamento, empregando-se um computador e software específico para tal finalidade, corroborando com Hoffmann e Hewitt (2005).

O número de pessoas que possuem um telefone celular vem aumentando, como indica a pesquisa realizada pelo Instituto Brasileiro de Geografia e Estatística (IBGE, 2011). A pesquisa aponta que de 2005 a 2011 houve um aumento de $107,7 \%$ no número de brasileiros que possuem um telefone celular. Segundo o jornal Estadão (2014), a informações divulgadas pela União Internacional de Telecomunicações indicam que o número de celulares até o final do ano se igualaria ao número de pessoas na Terra e em 2015 superaria esse número. Somente no Brasil, no primeiro trimestre de 2015, foram vendidos 14,1 milhões de smartphones, sendo que 90\% destes possuíam sistema operacional Android (TECMUNDO,2015).

O Android é um sistema operacional livre disponibilizado pela empresa Google, voltado para dispositivos móveis e baseado em Linux. Este poderoso sistema possui código aberto e funciona em diversos dispositivos, tais como smartphones e tablets (MONTEIRO, 2012; LECHETA, 2013). O Google fornece uma API de desenvolvimento para esse sistema, o que representa uma grande oportunidade na criação de novas aplicações inovadoras que possam estar cada vez mais, espaIhadas por todos os dispositivos do mundo. 


\section{V.2, N.1, 2018}

Visando facilitar estas avaliações em campo, objetivou-se com este trabalho desenvolver um aplicativo em plataforma Android para analisar as etiquetas hidrossensíveis e determinar os parâmetros da pulverização, sendo estes, a densidade de gotas por unidade de área e o diâmetro mediano volumétrico (DMV).

\section{REFERENCIAL TEÓRICO}

O uso de agrotóxicos, embora seja responsável pela redução das perdas na produção agrícola em função do controle de insetos, patógenos e plantas daninhas, pode ser questionável devido ao risco de contaminação ambiental proporcionado pelo potencial de perdas de produtos para o meio ambiente. Na maioria das vezes, dá-se muita importância ao produto fitossanitário a ser aplicado e pouca atenção à tecnologia de aplicação. No entanto, além de conhecer o produto a ser aplicado, também é necessário dominar a forma adequada de aplicação, de modo a garantir que o produto alcance $o$ alvo de forma eficiente, minimizando-se as perdas (CUNHA et al., 2005).

Empregando-se a tecnologia de aplicação, devemos selecionar corretamente o equipamento, regular e calibrar, verificar as condições meteorológicas no momento da pulverização, bem como avaliar se a pulverização está sendo realizada de maneira correta. Observa-se que se trata de um sistema complexo. Sendo assim, diversas técnicas têm sido desenvolvidas para auxiliar durante este processo.

Sasaki et al. (2013) desenvolveram um Aplicativo em Android para auxiliar a calibração de pulverizadores em campo. Alvarenga et al. (2013) desenvolveram um sistema automático para controle do espectro em um pulverizador hidropneumático de acordo com as condições psicrométricas do ar no momento da pulverização. Nesta mesma linha de pesquisa, Doruchowski et al. (2009) automatizou um sistema pulverizador pneumático para amenizar as perdas para o meio ambiente.

Outro aspecto importantíssimo e que engloba a tecnologia de aplicação é a avaliação da pulverização, se a mesma está sendo correta ou não. Geralmente, em campo esta avaliação é realizada por meio de etiquetas hidrossensíveis. Diversos softwares são empregados nesta etapa, a exemplo o E-Springle, ImageTool, CIR, etc. $\mathrm{O}$ grande entrave para avaliar as etiquetas por meio destes softwares, é a necessidade de uma mão de obra qualificada, bem como a necessidade de digitalizar as etiquetas para posterior análise, o que na prática podese tonar o entrave para o seu uso.

No campo das aplicações de Visão Computacional, a extração de objetos de interesse em uma imagem tem extrema importância, uma vez que pode ser utilizada como deteç̧ão, reconhecimento, identificação e rastreamento. Após a extração do objeto de interesse, a partir de uma imagem digital, é possível a sua posterior análise de maneira automática (OJI, 2012).

O OpenCV (Open Source Computer Vision Library) é uma biblioteca de Visão Computacional open source composta por centenas de algoritmos nela incluídos, além disso, é uma biblioteca multiplataforma, implementada em $\mathrm{C}++$ e que possui diversos métodos úteis no Processamento Digital de Imagens e na Visão Computacional. (KINJO \& SOARES, 2013). As técnicas aplicadas neste presente trabalho, referências, funcionalidades e utilização são descritas por BRADSKI \& KAEHLER (2008).

Segundo GONZALEZ \& WOODS (2010) limiarização é um processo de segmentação de imagens que utiliza o tom de cinza em diferentes pontos da imagem para posteriormente, a partir de um limiar estabelecido, isolar os objetos de interesse. A imagem segmentada é divida em dois tons: o grupo de pixels com níveis acima do limiar e o grupo de pixels abaixo do limiar. Após a aplicação da limiarização, a imagem se torna binária, ou seja, o valor se torna fixo para todos os pixels de cada grupo na imagem.

Dentre as muitas técnicas de melhoramento utilizadas no Processamento Digital de Imagens, estão as operações de morfologia matemática, que são utilizadas para remoção de pequenos pontos e preenchimento de buracos aparentes nas imagens, os quais podem atrapalhar a detecção ao serem confundidos com os objetos de interesse.

Outras importantes funções da biblioteca OpenCV utilizadas nesse trabalho são as operações que possuem como objetivo a identificação dos contornos existentes na imagem limiarizada, e o método para desenhar o contorno nas manchas identificadas. Para o cálculo da área e seus respectivos parâmetros necessários na análise das etiquetas, foram utilizadas fórmulas matemáticas definidas na metodologia.

O trabalho tem o objetivo de auxiliar na avaliação da qualidade da pulverização em campo. Realizar a correta aplicação, automaticamente, ameniza-se os impactos ambientais, reduz custos ao produtor rural e menores são as chances de deixar resíduos nos alimentos. Ain- 


\section{V.2, N.1, 2018}

da, desenvolvendo-se um aplicativo Android, aumenta-se a viabilidade do uso, uma vez que os softwares específicos para este fim apresentam elevado custo de aquisição, necessidade de um computador, além da necessidade de uma mão de obra qualificada. Já, empregando-se um aplicativo Android, reduzirá o custo de aquisição, bem como, facilidade no uso.

\section{MATERIAL E MÉTODOS}

A pesquisa foi realizada no Laboratório de Informática e no Laboratório de Mecanização Agrícola do Instituto Federal de Minas Gerais, Campus Bambuí, Bambuí - MG. O software foi desenvolvido com o auxílio de um Notebook, marca Gateway, modelo NE56R06b.

Inicialmente, instalaram-se no computador os softwares Eclipse versão Kleper e configurou-o com as bibliotecas Android. Utilizou-se a biblioteca de visão computacional OpenCV (versão 3.0.0), integrada ao ambiente de desenvolvimento da Fundação Apache, Eclipse Kleper na linguagem de programação Java para plataforma Android. Após a associação do ambiente de desenvolvimento e a biblioteca, desenvolveu-se a interface do aplicativo (Figura 1A) utilizando-se a linguagem de marcação XML (Extensible Markup Language).

A tela principal, foi composta com um ícone denominado "Selecionar imagem", por sua vez, foi programado para abrir uma janela de opções (Figura 1B). A opção "Instruções" demonstra ao usuário passo-a-passo o roteiro para utilizar o aplicativo. Para maior precisão na análise da imagem, o ícone "Ajustar dimensões" possibilita colocar o tamanho real da etiqueta em centímetros (Largura e Altura). A opção para "Adicionar da galeria" é utilizada para o usuário inserir a imagem a ser analisada e por último a opção de "Cancelar".

O aplicativo foi desenvolvido de tal modo que, para o usuário realizar a análise de uma etiqueta hidrossensível no campo, o mesmo deve tirar uma fotografia com o aparelho móvel, e, se necessário, com as próprias ferramentas de edição de imagem do aparelho, recortar a imagem a ser analisada. Em seguida, abre-se o aplicativo, escolhe-se o ícone selecionar imagem, adicionar da galeria, e se for o caso, ajustar as dimensões da etiqueta. Todas as alterações que o usuário realiza, o aplicativo salva e automaticamente retorna a tela inicial.

De posse da imagem selecionada, o usuário deverá selecionar o segundo ícone da tela inicial "Analisar Imagem". Este ícone foi associado à rotina de análise da imagem de etiqueta presente no aplicativo. Por padrão, o Android trabalha com imagens do tipo Bitmap, e a biblioteca de Visão Computacional OpenCV trata as imagens com extensão do tipo Mat. Sendo assim, foi programado para a conversão automática da imagem. Após a aquisição da imagem, com base no trabalho desenvolvido por Smith (1974), aplicou-se um filtro em tons de cinza, isso é feito porque a técnica de limiarização utilizada necessita de imagens neste formato para em seguida, realizar um threshold da imagem.

Após a etapa de thresholding, para a detecção das gotas de forma mais precisa foi necessária a aplicação de filtros morfológicos, sendo principalmente, as operações de erosão e dilatação. Foi aplicado uma abertura morfológica (erosão seguida de dilatação), e o elemento estruturante utilizado foi uma elipse de raio de 2 pixe/s. Usando a imagem binária resultante foi aplicada a função para identificar os contornos presentes na imagem, para isso foi considerado que as partes em branco da imagem representam locais que existem alguma gota (objeto) e as partes com coloração preta representam o fundo.

Para minimizar os erros durante a análise das imagens, elaborou um roteiro de modo a relacionar os tamanhos aparente (R) e real ( $\left.R^{\prime}\right)$ do objeto, conservando-se as proporções reais da imagem a ser analisada, minimizando o efeito de distorção da imagem. Após obtidos os valores dos diâmetros em pixels e convertê-los para centímetros, determinou a área do objeto. Com base na área da imagem determinou-se o volume do objeto, representado por uma gota. Foi aplicado o fator de correção de espalhamento, conforme recomendações de alguns fabricantes de etiquetas hidrossensíveis.

Com o valor final de área e volume de cada gota, os mesmos foram armazenados, identificados e ordenados em volume crescente para determinação do Diâmetro mediano volumétrico (DMV), onde, de forma linear, os volumes das gotas eram ponderados até encontrar a gota mediana que separa o volume total das gotas coletadas em duas partes iguais.

Ao final dos processamentos, uma caixa de diálogo é aberta com os resultados obtidos. $\mathrm{O}$ aplicativo fornece as dimensões da etiqueta $(\mathrm{cm})$, quantidade de gotas encontrada na imagem, diâmetro médio $(\mu \mathrm{m})$, DMV $(\mu \mathrm{m})$, densidade de gotas (gotas $\mathrm{cm}-2$ ).

Com o aplicativo desenvolvido, prosseguiram-se as avaliações. Para isto, obtiveram-se aleatoriamente cinco etiquetas hidrossensíveis, com dimensão de 2,54 x 2,5 


\section{V.2, N.1, 2018}

cm (Altura e Largura). Com o auxílio de um pulverizador costal realizaram-se as pulverizações com água sob a mesma, com diferentes padrões de coberturas (Figura 2).

De posse destas etiquetas, foram submetidas à análise por três aparelhos móveis e um simulador (SAMSUNG GT-S7560Ml; SAMSUNG GT-I8552B; LG-E455f e Simulador Android BlueStacks) e realizaram-se as análises pelo aplicativo. Para averiguar a confiabilidade do sistema proposto, a mesma etiqueta foi submetida a análise 4 vezes por um mesmo aparelho, comparando os resultados obtidos. Todo o experimento foi realizado em delineamento inteiramente casualizado, em esquema fatorial (5×4), cinco etiquetas hidrossensíveis e quatro aparelhos móveis, com 4 repetições por tratamento. Os valores obtidos foram tabulados e submetidos a análise descritiva por meio do software Assistat, $v 7.7$, beta.

\section{RESULTADOS E DISCUSSÃO}

Ao selecionar a imagem da etiqueta e executar os procedimentos de análise, o aplicativo fornece como resultado uma caixa de texto contendo as informações obtidas pelo processamento (Figura 3).

$\mathrm{Na}$ análise de confiabilidade dos resultados, durante as diferentes repetições realizadas, para um determinado modelo e marca de dispositivo móvel, observou-se boa repetibilidade dos valores com variação nula entre as diferentes repetições realizadas, mostrando que a metodologia definida para detecção de gotas é eficiente e confiável.

Logo, como a variabilidade dos resultados foi nula durante as diferentes repetições, na análise de variância, a soma de quadrados do resíduo foi igual ou próximo do valor zero. Sendo assim, não permite o desdobramento dos fatores e a aplicação do teste de média entre os diferentes tratamentos, optando-se em realizar todas as análises descritivas. Este fato é importante e significa que inserindo o dado corretamente (tamanho da etiqueta), independente do usuário, o resultado deverá ser o mesmo. Ainda, para um determinado aparelho móvel, o aplicativo foi testado em diferentes tamanhos de tela e obteve êxito em todas as análises, devido o fato da interface ter sido projetada para se adequar de acordo com a resolução proporcionada pelo aparelho.

Ao se avaliar uma determinada etiqueta entre os diferentes dispositivos móveis, houve pequena variação entre os resultados, com coeficiente de variação de no máximo $11,15 \%$ (Tabela 1).
Observou-se que para um determinado fabricante de aparelho móvel, independente do modelo do apareIho, não houve variabilidade dos resultados ao alterar as etiquetas. Já ao se alterar o fabricante, houve pequenas variações nos resultados. Isto se deve provavelmente a maneira de como cada arquitetura trata o ponto flutuante, que se propaga no decorrer das operações matemáticas realizadas pelo aplicativo. Outra possibilidade nas pequenas diferenças encontradas pode estar associada a resolução da tela do aparelho móvel. Souza et al. (2008) relatam que quanto maior a resolução utilizada, maior será a quantidade de pontos identificado na imagem.

A maior variabilidade entre as avaliações, comparando os diferentes aparelhos, ocorreu na Etiqueta 3, com coeficiente de variação de $11,15 \%$. A Etiqueta 3 foi a que apresentou a maior densidade de gotas e cobertura, e a variabilidade dos resultados podem estar associados como cada fabricante processa e analisa a coalescência entre uma gota e outra, diferindo-se os valores obtidos. Nascimento et al. (2013) e Marçal e Cunha (2008) relataram que um volume de pulverização alto, pode unificar as gotas impossibilitando a leitura pelo software.

Para minimizar os erros, quando se deseja altíssimas precisões nos resultados, em campo, o usuário poderá trabalhar com a média dos resultados de um número de amostras, ou seja, etiquetas (NASCIMENTO et al., 2013). Por exemplo, para a cultura do café, para resultados satisfatórios, Vitório e Campanharo (2016) recomendam o número de 9 etiquetas por planta.

De acordo com os resultados obtidos, detectou-se ainda que para o simulador BlueStacks, em todas as análises realizadas, apresentou maiores valores para os parâmetros técnicos da pulverização. Este fato pode ter ocorrido, pois o BlueStacks utiliza um computador para fazer as simulações de um aparelho móvel, o que pode alterar as condições de processamento diferindo os resultados das análises.

Garcia et al. (2004) compararam diferentes programas computacionais para análises de etiquetas hidrossensíveis e detectaram valores altíssimos de variação entre um software e outro. Cunha et al. (2013) em estudos semelhantes também constataram valores diferentes entre um software e outro de acordo com a etiqueta analisada. Já o aplicativo desenvolvido, mostrou coeficiente de variação máximo de $11,15 \%$, demonstrando alto potencial para ser utilizado em campo.

Nos resultados do tamanho de gotas (DMV), ob- 


\section{V.2, N.1, 2018}

servou-se que o máximo coeficiente de variação foi de $3,53 \%$, demonstrando valores muito próximos entre um aparelho e outro. Pode-se verificar que as diferenças nos resultados, esta associado às menores gotículas durante as análises de imagens, uma vez que houve maior variabilidade dos resultados no parâmetro densidade de gotas e pouca variabilidade no DMV.

A qualidade de uma aplicação de agrotóxicos está relacionada à deposição sob o alvo. Os papéis hidrossensíveis são muito utilizados em ensaios práticos a campo para determinar o tamanho de gotas via programas computacionais, os quais analisam o espalhamento da área molhada sobre o alvo artificial digitalizado (BAIO, et al., 2015). Deve-se ressaltar que as avaliações realizadas em campo, é complicada, pois quando deseja-se uma análise criteriosa deve-se utilizar softwares computacionais e requer mão de obra qualificada. Adotando-se o aplicativo, as análises ficarão muito mais acessíveis, principalmente aos produtores rurais.

Quando se trabalha com processamento digital de imagens, as ferramentas computacionais requerem alto potencial de softwares e hardwares. O aplicativo desenvolvido, utilizou a biblioteca OpenCV que possui algoritmos otimizados para reduzir o gasto com o processamento, permitindo a utilização do programa com dispositivos móveis com baixa capacidade de processamento, necessitando apenas do sistema operacional Android.

Os dispositivos móveis estão cada vez mais acessíveis. Utilizando-se o aplicativo desenvolvido diminuirá o tempo para as análises das etiquetas, favorecendo as avaliações das pulverizações, aumentando-se assim a qualidade e a eficiência das aplicações. Para o produtor rural gera economia com gastos de agrotóxicos e reduz os impactos ambientais.

Diante da grande portabilidade e facilidade no uso do aplicativo, é possível o responsável técnico do campo, analisar instantaneamente se está ocorrendo a deposição de gotas sob alvo, e pode-se identificar problemas relacionados ao ajuste do pulverizador como, por exemplo, ponta de pulverização hidráulica desajustada, pressão imprópria e outros parâmetros inerentes ao processo de pulverização (SOUZA et al., 2008).

\section{CONCLUSÃO}

O presente trabalho demonstrou que a o aplicativo desenvolvido com a utilização do OpenCV para aplicação de detecção, contagem e cálculo do diâmetro mediano volumétrico em etiquetas hidrossensíveis apresentaram resultados satisfatórios;

O aplicativo auxilia o profissional do campo, pois possui boa portabilidade computacional, e de baixo custo. Possui interface simples, interativa e de fácil utilização, requerendo pouco conhecimento técnico em informática.

O coeficiente de variação máximo obtido entre os diferentes dispositivos móveis avaliados foi de $11,15 \%$, valor considerável sabendo-se da pouca quantidade de softwares disponíveis que possuem esse tipo de aplicabilidade. 


$$
\text { V.2, N.1, } 2018
$$

\section{REFERÊNCIAS}

BAESSO, M. M. et al. Tecnologias de aplicação de agrotóxicos. Revista Ceres, Viçosa, v. 61, Suplemento, p. 780-785, 2014.

BAIO, F. H. R. et al. Papel hidrossensível e alternativo fotográfico em ensaios de deposição de gotas. Brazilian Journal of Biosystems Engineering, v. 9, n. 4, p. 339-347, 2015.

BRADSKI, G. \& KAEHLER, A. Learning OpenCV. Sebastopol: O'Reilly, 2008. $555 \mathrm{p}$.

CUNHA, J. P. A. R. et al. Computer Programs for Analysis of droplets sprayed on Water Sensitive papers. Planta Daninha, v. 31, n. 3, p. 715-720, 2013.

GARCIA, L. C. et al. Avaliação de softwares para análise de parâmetros da pulverização realizada sobre papéis hidrossensíveis. Revista Brasileira de Agrocomputação, v. 2, n. 1, p. 19-28, 2004.

GONZALEZ, R. C. \& WOODS, R. C. Processamento de imagens digitais. 3. ed. São Paulo: Pearson Prentice Hall, 2010. 624p.

HOFFMAN, W. C.; HEWITT, A. J. Comparison of Three Imaging Systems for water-sensitive papers. Applied Engineering in Agriculture, v. 21, n. 6, p. 961964, 2005.

KINJO, P. \& SOARES, T. OpenCV rastreando objetos, 2013. Disponível em: <http://www.academia. edu/4654828/OpenCV_Rastreando_Objetos> Acesso em: 13 set. 2014.

LECHETA, R. R. Google Android: aprenda a criar aplicações para dispositivos móveis com o Android SDK. 3. ed. São Paulo: Novatec Editora, 2013.

MARÇAL, A. R. S.; CUNHA, M. Image processing of artificial targets for automatic evaluation of spray quality. Transactions of the Asabe, v. 51, n. 3, p. 811-821, 2008.

MONTEIRO, J. B. Google Android: crie aplicações para celulares e tablet. São Paulo: Casa do Código, 2012.
OJI, R. An automatic algorithm for object recognition and detection based on ASIFT keypoints. Signal \& Image Processing: An International Journal. v. 2, n. 5, Out. 2012

PESSOA, M. C. P. Y.; CHAIM, A. Programa computacional para estimativa de uniformidade de gotas de herbicidas aplicados por pulverização aérea. Pesquisa Agropecuária Brasileira, Brasília, v. 34, n. 1, p. 45-56, 1999.

RODRIGUES, E. B. et al. Deriva de equipamentos costais na aplicação de Glyphosate. Revista Brasileira de Engenharia Agrícola e Ambiental, Campina Grande, v. 19, n. 10, p. 1012-1017, 2015.

SILVA, J. E. R. et al. Deposição de calda em folhas de cafeeiro e perdas para o solo com diferentes taxas de aplicação e pontas de pulverização. Revista de Engenharia Agrícola e Ambiental, Campina Grande, v. 18, n. 12, p. 1302-1306, 2014.

SOUZA, J. A. R. et al. Programa computacional para estimativa da uniformidade de gotas na pulverização agrícola. Engenharia na Agricultura, Viçosa, v. 16, n. 4, p. 458-464, 2008.

TECMUNDO. Android ocupa $90 \%$ dos $14 \mathrm{mi}-$ Ihões de smartphones vendidos no Brasil em 2015. Disponível em: <http://www.tecmundo.com.br/celular/ 81164-android-ocupa-90-14-milhoessmartphones-vendidos-brasil-2015.htm>. Acesso em: 04 jan. 2019.

TURNER, C. R.; HUNTINGTON, K. The use of water sensitive dye for the detection and assessment of small spray droplets. Journal of Agricultural Engineering Reserch, v. 15, n. 4, p. 385-387, 1970.

VITÓRIO, E. L.; CAMPANHARO, A. Amostra de etiquetas de papel hidrossensíveis para determinação de espectro de gotas em pulverização no cafeeiro Canephora. Coffee Science, Lavras, v. 11, n. 3, p. 367373, 2016. 


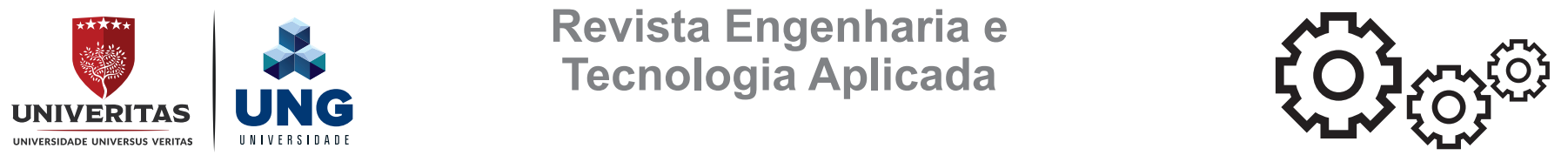

APLICATIVO ANDROID PARA AVALIAR A QUALIDADE DA PULVERIZAÇÃO EM CONDIÇÕES DE CAMPO Bruno Alberto Soares Oliveira, Servilio Assis, Robson Shigueaki Sasak

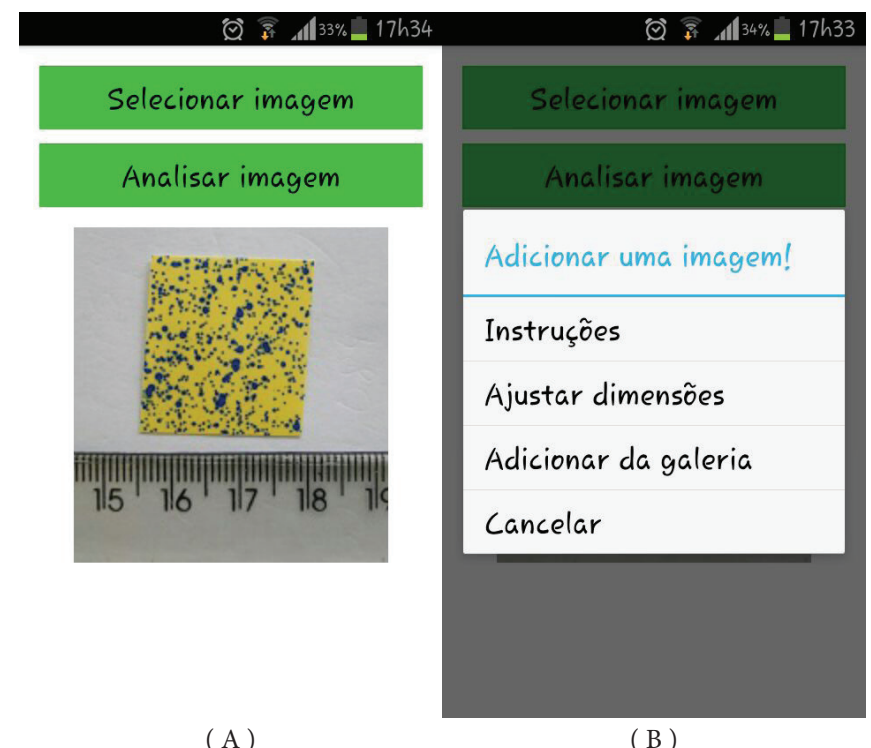

Figura 1. Desenvolvimento do aplicativo para análise de etiquetas hidrossensíveis. (A) Interface inicial do aplicativo. (B) Opções disponíveis ao selecionar imagem.

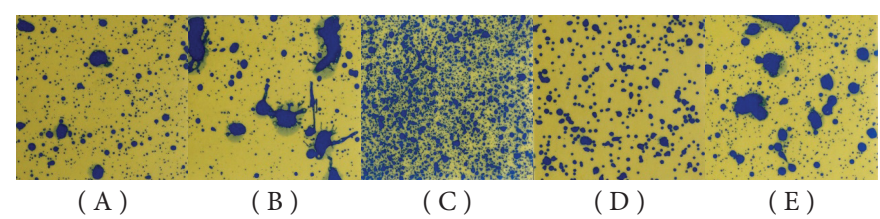

Figura 2. Etiquetas analisadas. (A) Etiqueta 1; (B) Etiqueta 2; (C) Etiqueta 3; (D) Etiqueta 4; (E) Etiqueta 5.

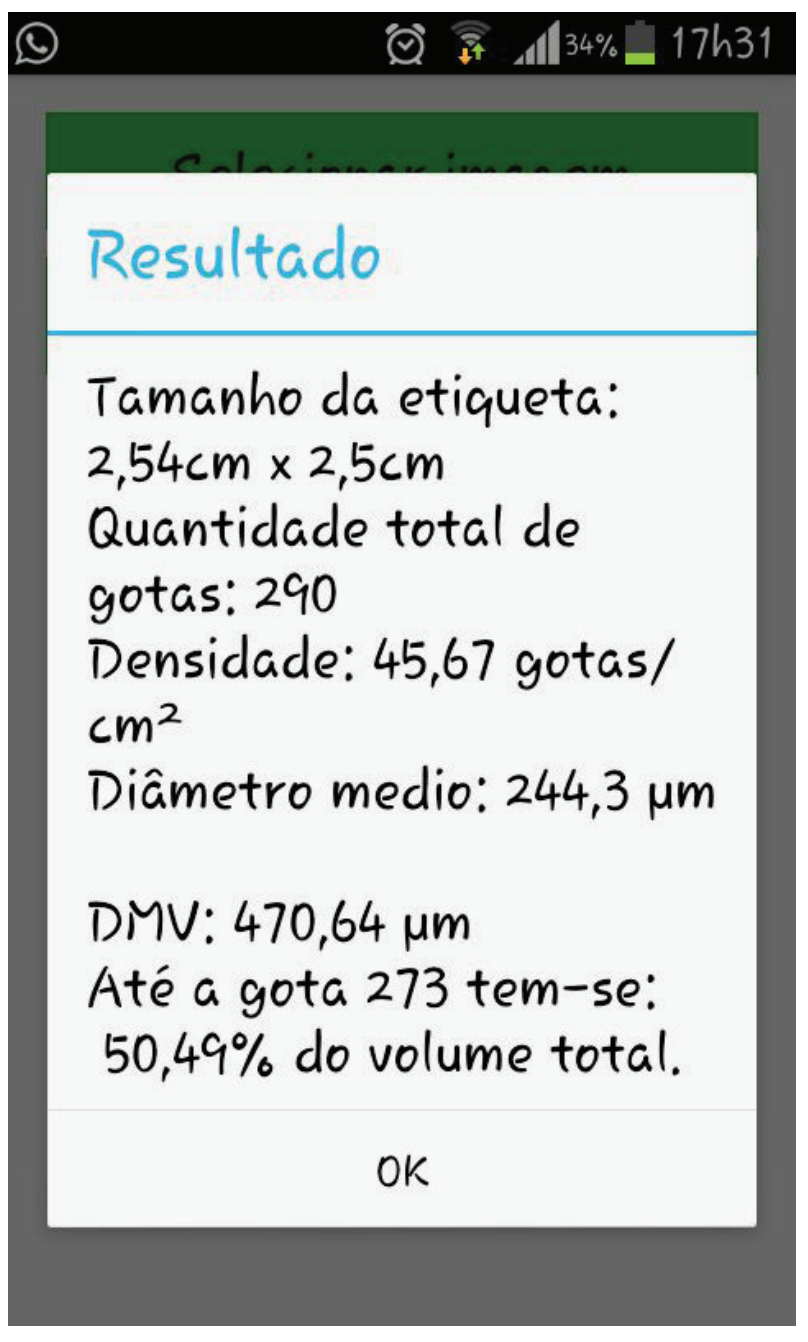

Figura 3. Resultados obtidos após análise. 
APLICATIVO ANDROID PARA AVALIAR A QUALIDADE DA PULVERIZAÇÃO EM CONDIÇÕES DE CAMPO Bruno Alberto Soares Oliveira, Servilio Assis, Robson Shigueaki Sasaki

$$
\text { V.2, N.1, } 2018
$$

Tabela 1. Resultados das análises das etiquetas hidrossensíveis submetidas a diferentes aparelhos móveis.

\begin{tabular}{|c|c|c|c|c|}
\hline Etiqueta & Dispositivo Móvel & Quantidade de gotas & $\begin{array}{l}\text { Densidade de gotas } \\
\quad\left(\text { gotas } \mathrm{cm}^{-2}\right)\end{array}$ & $\mathrm{DMV}(\mu \mathrm{m})$ \\
\hline \multirow{4}{*}{ Etiqueta 1} & SAMSUNG GT-S7560M & 688 & 108,35 & 1048,7 \\
\hline & SAMSUNG GT-I8552B & 688 & 108,35 & 1048,7 \\
\hline & BlueStacks & 759 & 119,37 & 994,55 \\
\hline & LG-E455f & 691 & 108,82 & 1048,7 \\
\hline C.V. $(\%)$ & & 4,96 & 4,89 & 2,62 \\
\hline \multirow{4}{*}{ Etiqueta 2} & SAMSUNG GT-S7560M & 348 & 54,8 & 2259,3 \\
\hline & SAMSUNG GT-I8552B & 348 & 54,8 & 2259,3 \\
\hline & BlueStacks & 417 & 65,67 & 2272,4 \\
\hline & LG-E455f & 350 & 55,12 & 2258,1 \\
\hline C.V. $(\%)$ & & 9,35 & 9,35 & 0,30 \\
\hline \multirow{4}{*}{ Etiqueta 3} & SAMSUNG GT-S7560M & 1162 & 182,99 & 2416,6 \\
\hline & SAMSUNG GT-18552B & 1162 & 182,99 & 2416,6 \\
\hline & BlueStacks & 1434 & 225,83 & 2588 \\
\hline & LG-E455f & 1156 & 182,05 & 2410,7 \\
\hline C.V. $(\%)$ & & 11,15 & 11,15 & 3,53 \\
\hline \multirow{4}{*}{ Etiqueta 4} & SAMSUNG GT-S7560M & 281 & 44,25 & 547,22 \\
\hline & SAMSUNG GT-18552B & 281 & 44,25 & 547,22 \\
\hline & BlueStacks & 286 & 45,04 & 525,68 \\
\hline & LG-E455f & 281 & 44,25 & 545,26 \\
\hline C.V. $(\%)$ & & 0,89 & 0,89 & 1,94 \\
\hline \multirow{4}{*}{ Etiqueta 5} & SAMSUNG GT-S7560M & 595 & 93,7 & 1622,4 \\
\hline & SAMSUNG GT-I8552B & 595 & 93,7 & 1622,4 \\
\hline & BlueStacks & 669 & 105,35 & 1638,5 \\
\hline & LG-E455f & 592 & 93,23 & 1621 \\
\hline C.V. (\%) & & 6,12 & 6,12 & 0,51 \\
\hline
\end{tabular}

C.V. = Coeficiente de Variação 